\title{
Children Should Be Seen and Heard: A Qualitative Analysis of Abuse Histories Provided by Children with Ano-Genital Injury Consistent with Sexual Contact
}

\author{
Marcella M. Donaruma-Kwoh1", K. K. Lopez ${ }^{1}$, A. N. Bachim¹, A. T. Cruz ${ }^{2,3}$, C. S. Greeley ${ }^{1}$ \\ ${ }^{1}$ Sections of Public Health Pediatrics, Baylor College of Medicine, Houston, TX, USA \\ ${ }^{2}$ Emergency Medicine, Department of Pediatrics, Baylor College of Medicine, Houston, TX, USA \\ ${ }^{3}$ Infectious Diseases, Department of Pediatrics, Baylor College of Medicine, Houston, TX, USA \\ Email: mmdonaru@texaschildrens.org
}

How to cite this paper: Donaruma-Kwoh, M. M., Lopez, K. K., Bachim, A. N., Cruz, A. T., \& Greeley, C. S. (2021). Children Should Be Seen and Heard: A Qualitative Analysis of Abuse Histories Provided by Children with Ano-Genital Injury Consistent with Sexual Contact. Advances in Applied Sociology, 11, 724-734.

https://doi.org/10.4236/aasoci.2021.1112059

Received: October 20, 2021

Accepted: December 27, 2021

Published: December 30, 2021

Copyright $\odot 2021$ by author(s) and Scientific Research Publishing Inc. This work is licensed under the Creative Commons Attribution International License (CC BY 4.0).

http://creativecommons.org/licenses/by/4.0/ (c) (i) Open Access

\begin{abstract}
Study Objective: To describe histories provided by sexually abused children whose ano-genital examinations demonstrated injury consistent with abuse. Design: This was a nested cohort study within a larger epidemiologic study of child sexual abuse. Setting: A large urban children's assessment center (CAC) medical clinic population seen in a single calendar year. Participants: Children aged 6 to 16 years who provided a medical history directly to a pediatric medical care provider. Main Outcome Measures: The elements of a history provided by abused children in the context of a corroborative physical exam were described through qualitative analysis. Results and Conclusions: Both school-aged children and adolescents identify their perpetrators, outline the mechanics of abusive contact, and can provide relevant details for medical and forensic evaluation. This was also true in the subgroup of children with learning disabilities and psychiatric comorbidities. Children shared an array of troubled emotions provoked by their abuse experience; narratives of resistance were more common in younger children, while older adolescents focused most on their fear. In this study, we demonstrate that abused children are able to share details of their sexual abuse experiences clearly, with abnormal exams supporting their disclosure narratives.
\end{abstract}

\section{Keywords}

Child Molestation, Child Molestation, Sexual, Molestation, Sexual, Child, Sexual Abuse of Child, Sexual Abuse, Child 


\section{Introduction}

Child sexual abuse (CSA) is an insidious form of maltreatment, with a wide range of psychiatric and psychosocial consequences that can persist into survivors' adulthood (Felitti et al., 1998). This type of abuse involves the inclusion of a child in sexual activities that the child cannot comprehend, for which the child is developmentally unprepared and cannot give consent, and/or that violate the law or social taboos of society (Donaruma, 2019). A survey of adolescents living in the United States reported that $14.3 \%$ of girls and $6.0 \%$ of boys disclosed a sexual assault during childhood (Finkelhor et al., 2015). This estimate of disease prevalence has been relatively stable across analyses, always manifesting a female predominance in endorsement of a sexual abuse experience (Pereda et al., 2009; Stoltenborgh et al., 2011). Pediatric care providers should address early intervention and prevention strategies that focus on avoiding recurrence of the abuse, typically in partnership with dual investigative agencies serving families and the justice system. This inter-professional relationship is challenged by the differences in focus for each partner. Medical personnel are trained to accept a patient history as the best method to organize the optimal evaluation and treatment plan, while investigators into child safety and protection require corroborative "evidence" to support the history of the present illness when sexual abuse is the primary complaint (Finkel et al., 2011; Adams et al., 2016; Shapiro \& Makoroff, 2006).

Inarguable proof that child sexual abuse has occurred, such as pregnancy or a sexually transmitted infection, is rarely detectable in the medical setting (Siegel et al., 1995; Heger et al., 2002). Physical exam discovery of ano-genital injury indicating sexual contact is similarly uncommon, found in about $5 \%$ of children who describe abuse (Kellogg et al., 2004; Anderst et al., 2009; Finkelhor et al., 2013). The child's history of an act that most often occurs in secret, witnessed only by the victim and the abuser, becomes the primary driver of the subsequent evaluation of the child's environment and caretakers. The sufficiency and clarity of a medical history that prompts a diagnostic clinical evaluation may not be perceived comparably by a caseworker, detective, or attorney due to uncertainty about the weight of the victim's history as "evidence."

Because the process of disclosure of a history of sexual abuse is often convoluted, a delayed disclosure is more common than an immediate outcry. Influences on the child historian are multifactorial and the nature of the relationship between victim and perpetrator may play a large role, especially when that assailant is a close family member, or even the family breadwinner (McElvaney et al., 2014; Hassan et al., 2015; Heyman et al., 2020). Further barriers are both interpersonal and intrapersonal, and can involve strong fears centering on blame, potential disbelief of their accounts, and the consequences that will follow the outcry, as well as shame related to the abuse, their delay in disclosing, and of revealing deeply personal information (Hassan et al., 2015). However, children in research scenarios tend to tell the truth when the information will be helpful to the recipient and uncommonly lie with the intent to manipulate others (Talwar 
et al., 2019; Oates et al., 2000). Truth-telling is also the pattern with adolescent sexual abuse victims; typically patients will under-report the extent of sexual contact, and rarely fabricate allegations (Sjöberg \& Lindblad, 2002; Finkel, 2008). The historical details of an abuse event, when shared through each abuse survivor's own unique perspective, can provide plausible insight into the child's experience, and this study aims to better characterize what may be expected and relied upon in that history. The goal of our study was to identify and characterize the elements of a sexual abuse history that children with corroborating physical exam findings provide to clinicians. This may help pediatric providers identify historic elements that can be sought as supporting a diagnosis of CSA and guide decision-making as well as efforts to engage social support for families.

\section{Methods}

\subsection{Setting and Study Population}

This was a nested cohort study within a larger epidemiologic study of CSA involving children aged 6 to 16 years referred to a large urban children's assessment center (CAC) medical clinic seen in a single calendar year (2009) (Greeley et al., 2016). This medical clinic accepts referrals from medical providers, family services caseworkers, and investigating law enforcement personnel when there are concerns for 1) sexual abuse outcry by a pediatric patient or 2) at-risk status due to some shared circumstance with a child who has made an outcry of sexual abuse victimization.

\subsection{Data Collection}

After obtaining a medical history from the caregiver, a clinic physician (one of 2 Emergency Medicine pediatricians or 2 Child Abuse pediatricians) obtained the history using open-ended and developmentally appropriate questions while the child sat in a private setting with the clinician, and the caregiver waited outside in the waiting room. The history was obtained and the elements directly related to the sexual abuse disclosure were documented verbatim prior to the physical examination which included colposcopic viewing of the anogenital area. Electronic health records were queried to identify patients with abnormal genital or anal examination findings. Examination findings were then reviewed for specificity for blunt force trauma according to generally accepted criteria (Adams, 2016). Institutional review board approval was obtained (H-33367). The retrospective nature of this chart review introduced minimal risk of harm to this vulnerable pediatric population.

Inclusion criteria consisted of an anogenital exam positive for signs of blunt force trauma as well as documentation of a history of present illness provided directly from the child. Charts of included patients were reviewed for demographics, including age, gender, race and ethnicity. The discussion of the history of present illness (HPI) between the child and examiner was coded for concepts and themes expressed by these children and documented verbatim by their ex- 
aminer during the visit. We identified 3 areas of interest a priori. First, could children identify the basic necessary information to direct a meaningful medical evaluation, such as the identity of their alleged perpetrator and the mechanics of contact? Second, could children provide a history of signs or symptoms associated with their abuse (e.g., pain, bleeding) to contribute to the interpretation of their physical exam? Finally, were there spontaneous elements of the history regularly described by this group of children?

\subsection{Analysis}

This qualitative study employed a secondary analysis of data originally collected to identify community characteristics associated with seeking medical evaluation for suspected child sexual abuse in a large urban area. The results are published elsewhere (Greeley et al., 2016). In this project, we returned to the data and asked a new research question focused on the content of pediatric medical histories of sexual abuse in those children with evidence of trauma to the anogenital area.

Patient histories were obtained thorough chart abstraction. Data were extracted, coded, and analyzed by individual coders using Glaser and Strauss's (1968) constant comparative method. The research team followed the Glaser and Strauss process of making iterative comparisons of the qualitative data. Using an adaptation of Seaver (2008)'s model: Stage 1: researchers reviewed chart abstraction data to identify keywords and phrases; Stage 2: researchers met to discuss their independent findings, aggregate codes, and identified connections between codes; Stage 3: researchers independently recoded chart abstractions with codes previously approved by team and Stage 4: reviewers met to identify, reconcile and refine coding differences through consensus (Glaser et al., 1968; Seaver et al., 2008). For example, expression of associated negative emotions' as a topic was refined as fear (for self), fear (for others), anger, disgust, and shame.

\section{Results}

During the study period, 785 children were evaluated for possible sexual abuse, of whom 31 (3.9\%) met inclusion criteria (Figure 1). Ninety percent were girls (Table 1), 58\% were Hispanic, and 23\% were prepubertal ( $<10$ years old) (Figure 2). Mental health conditions or learning disabilities were found in 35\% of the cohort, including all boys. The ability to provide a meaningful history independent of the caregiver was not associated with comorbid diagnoses or patient age. Both pre- and post-pubertal children could discuss not only the mechanics of the inappropriate contact, but also were able to provide information on circumstances surrounding their abuse as well as physical, psychological, and emotional responses to the events. Every child identified their alleged perpetrator, either by name or by relationship. Overall, children were able to describe the mechanics of their abuse, signs and symptoms related to the abusive contact(s), emotional associations with the abuse event(s), and even provide relevant details to direct both medical and forensic evaluation. 


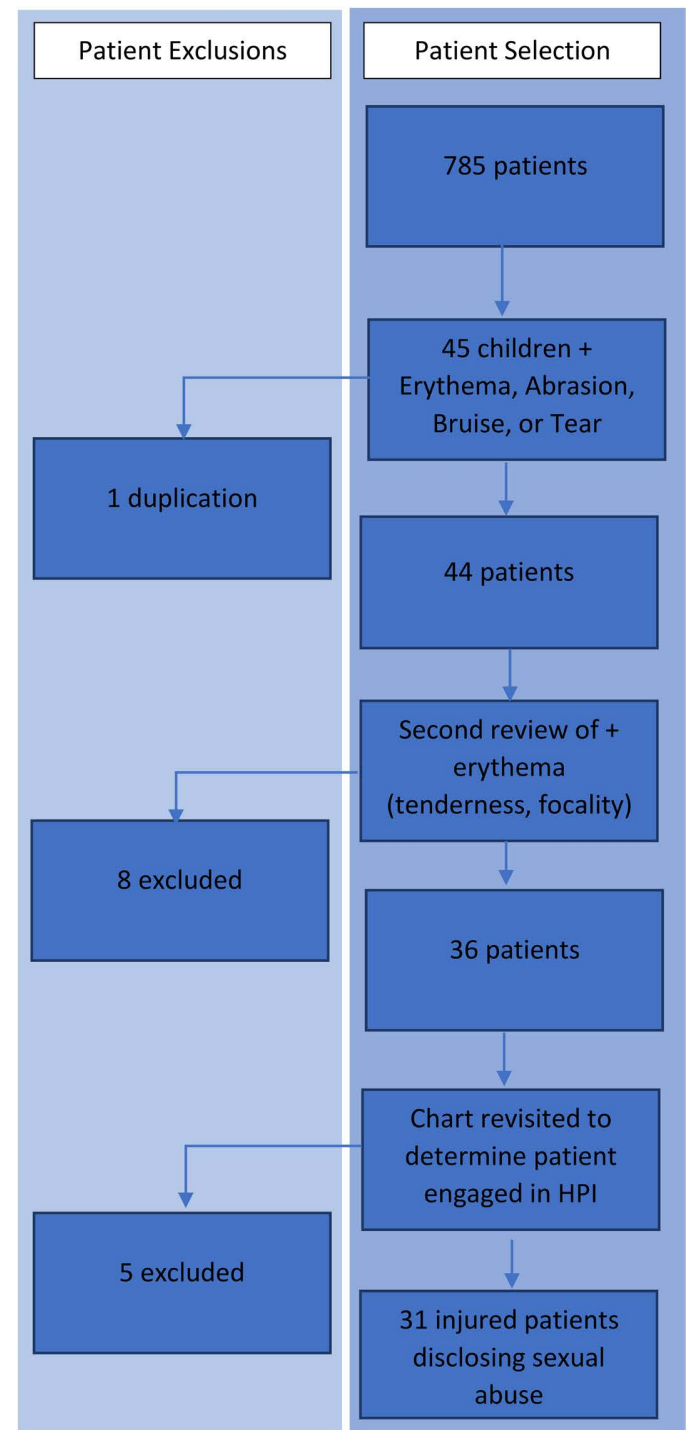

Figure 1. Identification of study population.

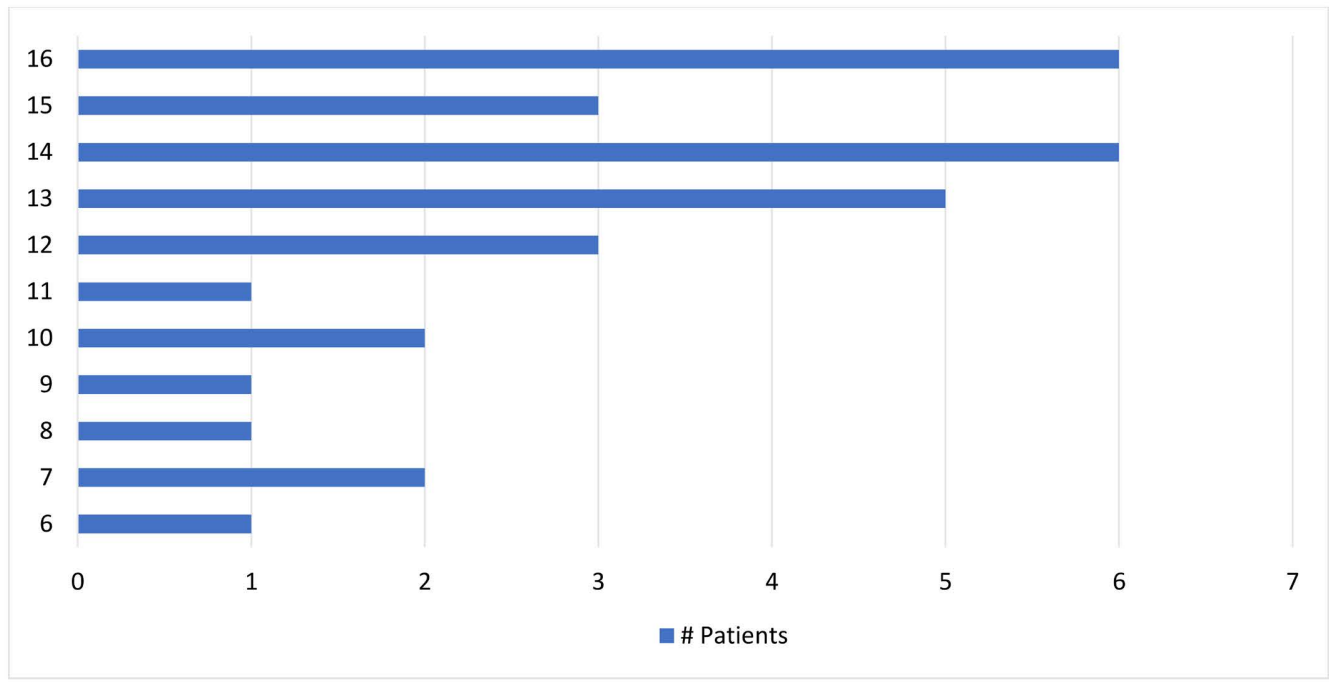

Figure 2. Age distribution of patients (years). 
Table 1. Population demographics.

\begin{tabular}{ccc}
\hline Category & Value & \\
& 12.7 (mean) & \\
Age (years) & 13 (median) \\
& Interquartile range $=4$ & \\
\hline Gender & $90.3 \%$ female & 58 \\
Race/Ethnicity (\%) & Hispanic Caucasian & 19 \\
& African-American & 19 \\
& Caucasian (non-Hispanic) & 3 \\
\hline
\end{tabular}

\section{Mechanics}

Even the youngest children in the group could describe specific mechanics surrounding their contact:

"His weiner ... in the hole and in the crack." age 6, male

"He took his private, and he just touched my crack and my mother she catched him, yes. Then his thing, his front part, then put it in my butt." age 7, F

"He did things with a hammer and my butt. He put the hammer's handle in my butt." age 10, $\mathrm{F}$

Older children could provide increasingly detailed accounts:

"Because somebody raped me, someone broke in and raped me. Someone forces you to have sex. He forced it in me. Forced his private in my private part." age $12, \mathrm{~F}$

"I was raped when someone puts their penis into your vagina and you don't want it." age $12, \mathrm{~F}$

"Then he either stuck his finger or his penis in me for like 40 or 50 minutes, then pulled my panties back up." age 15, $\mathrm{F}$

"I was forced into prostitution." age 16, F

\section{Signs and symptoms}

In addition, youngest children described painful associations with the contact, such as the 10-year-old girl mentioned above who experienced abuse with an object (hammer), who further described: "two times I bled out of my butt. It came out when I pooped." Another girl, aged 7, offered "it was hurtful" in regard to the digital genital contact she had experienced, without further elaboration, leaving it unclear if she was reflecting on physical or emotional pain, or a combination of both, as she described her abuse.

Older children also could describe the effects of the physical injury that was later noted on exam:

"It hurt and it bled a little." age 13, M (forced penile-anal contact)

"Then we went to my grandma's house and I was bleeding and there was blood on my panties and I had changed and took a shower." age 15, F (forced penile-vaginal contact)

"The hurting after urine, it started after that [the assault]." age 16, F (forced 
penile-vaginal contact)

\section{Recall of Response}

A trend in the context of the disclosure descriptions appeared with more accounts of resistance in the younger children in the face of force or its threat, but more reflections on their fear shown by the older children.

"He was trying to touch parts he shouldn't ... Trying. Only the butt, but I was protecting myself." age $7, \mathrm{~F}$

"I told him to get it out but he didn't and I couldn't stand it so I got my feet and I hurt him in his penis." age 9, F

"I had some bruises on my wrist, where I was trying to fight him off and he was hitting me." age $12, \mathrm{~F}$

"He told me not to tell: 'I gonna beat you up." age 13, M

"I know you supposed to tell, but I was too young, I was just 13 bout to be 14 and I was so scared." age $15, \mathrm{~F}$

"He come back and he laid down on the bed and he pull my gym shorts down and my panties down, and me, I $m$ terrified. And scared." age 15, F

In addition, a small number of children commented on disgust at the perpetrator's behavior:

"it felt nasty... Now he just sickens me and I can't be his friend." age 11, F

There was a small population of adolescents who described the sexual contact as a romantic aspect of a loving relationship with a partner who was an adult, underscoring the effectiveness of grooming. This perception began as early as age 12 (with a 29-year-old perpetrator) and through the adolescent years from 5 separate patients.

"He was there when my dad wouldn't listen. He listens to me and he understands what I am going through and everything." age 14, F regarding adult man in his 50 s

Finally, there was a group of children who provided medically and forensically relevant details about their contact, specifically in relation to exposure to bodily fluids:

"I felt, like a little wet spot on my side, it wasn't there before he did that and it was there after he did that." age 11, F

"Some kind of white stuff [ went] outside my body, on my tummy." age 13, F

"I think he nutted on me." age 15, F

\section{Discussion}

This qualitative study is the first of its kind to evaluate the nature of children whose sexual abuse is essentially proven by their physical exam findings. Sexual abuse is common, and normal physical examinations are found in up to $95 \%$ of children reporting sexual abuse (Kellogg et al., 2004; Anderst et al., 2009; Finkelhor et al., 2013). As such, historical details provided by the child are crucial to protective actions. Doubt is often cast on the ability of a child to provide a history, due to limited ability to communicate sexual abuse, lacking the context to 
realize the contact was inappropriate, or fearing the consequences of disclosure. The confluence of these circumstances can result in challenges to individual child safety when doubt is wrongly introduced based on a normal exam as well as on a larger scale when perpetrators avoid prosecution because a child's outcry as the sole eyewitness is the only proof that a crime took place.

By focusing on a cohort of children in whom there were definitive physical signs of sexual assault, we identified several themes. First, all school-aged children could provide detailed accounts as to the history and their signs and symptoms of the sexual contact. Older children generally could provide increasingly detailed accounts, as would be expected developmentally. Adolescents demonstrated a better understanding of sexual topics and the recognition of their own experience as socially inappropriate behavior by the perpetrator. Older children used more conceptual or euphemistic phrases to describe their encounters and moved away from descriptions at the level of body parts with increasing age. The choice to use a more socially bland phrase such as "intercourse" rather than more emotionally fraught terms such as "rape" or "molest" could reflect some socialization toward "polite" conversation with the adult examiner. Alternatively, this use of euphemisms may reflect an implementation of "the language of the unsayable", a practice of modulating the intensity of emotions that may accompany the disclosure of difficult and disturbing memories (Sorsoli et al., 2010; Sika-Bright et al., 2013).

Second, the elements of self-defense presented only in the narratives of younger children. It is not clear exactly why this trend is present, though small sample size may be the answer. Alternatively, the inclusion of this information may represent a desire of the child to demonstrate that she was not choosing to be involved in contact that has since been labeled as inappropriate. Or, describing an accompanying relative show of strength could be a compensation for feelings of anxiety that occur when disclosing her victimization (Scott et al., 2020). Implementation of a rudimentary "smokescreen technique" to redirect attention from the uncomfortable recollection of the abuse mechanics may also be at play (Sorsoli et al., 2010).

Lastly, reinforcing known data regarding the victimization of vulnerable children, thirty-five percent $(n=11)$ of the children in this group suffered from mental health conditions and/or learning disabilities, including all three of the male patients. However, having a comorbid diagnosis did not impair the ability of these members of the study group to provide a detailed history of molestation independent of their caregiver.

Protective action for these patients may be instigated by medical providers, but must be implemented by cooperative action between investigators outside of medical field. Early intervention and improved protection of child victims may be enhanced with a more refined concept regarding what constitutes a clear and plausible history of sexual abuse from a pediatric patient.

This is the first study to detail disclosure content from pediatric patients with corroborating anogenital findings who can describe their sexual abuse to doc- 
tors. Perhaps this description can assist investigators from law enforcement and child protection agencies to interpret the information they receive in the course of their work protecting potential child victims. Next steps to explore this topic should include more analysis of children younger than 10 on a larger scale, as well as closer scrutiny of the outcries made by male patients, who were a smaller percentage of this study population.

Our study had some limitations. The cohort of children was small, reflective of the rarity of anogenital injury following child sexual abuse. Given the retrospective nature of the study, as well as differences in patient age, data elements were not uniformly collected. Analyses depended on the physician skill set during the history of present illness and clinicians' charting habits. While recall bias is concern, $55 \%$ of cases were acute assaults $(<7$ days since the incident), potentially reducing the impact of recall bias. Additionally, the data set is ten years old, collected as part of a prior study. However, no changes in the epidemiology of child sexual abuse have been described in the intervening years, so this analysis may be relied upon in the context of current practices in the field.

\section{Conclusion}

This analysis demonstrates the elements of a history that can be provided by a child sexual abuse victim with corroborating injuries; pediatric patients can provide a history with sufficient detail to formulate a treatment plan and provoke reasonable concern for the safety of their environment. In the United States, the "Start by Believing" educational initiative has celebrated a decade in furthering understanding of the complicated circumstances surrounding abuse disclosures. Here, physical exam findings that do in fact support the disclosure history may encourage clinicians to believe and act on CSA narratives from pediatric patients. Further, it is important to recognize that many histories provided by uninjured children with disclosures of sexual abuse contain similar features to these children whose bodies display "proof" that the contact occurred. Ongoing attempts to characterize the elements of a plausible account of sexual abuse are warranted.

\section{Funding}

This research did not receive any specific grant from funding agencies in the public, commercial, or not-for-profit sectors.

\section{Conflicts of Interest}

This research did not receive any specific grant from funding agencies in the public, commercial, or not-for-profit sectors. Dr. Donaruma-Kwoh previously has provided expert witness consultation in the field of child abuse pediatrics for a fee. Dr. Cruz receives payment from the American Academy of Pediatrics for her role as associate editor for Pediatrics. 


\section{References}

Adams, J. A., Kellogg, N. D., Farst, K. J. et al. (2016). Updated Guidelines for the Medical Assessment and Care of Children Who May Have Been Sexually Abused. Journal of Pediatric and Adolescent Gynecology, 29, 81-87. https://doi.org/10.1016/j.jpag.2015.01.007

Anderst, J., Kellogg, N., \& Jung, I. (2009). Reports of Repetitive Penile-Genital Penetration Often Have No Definitive Evidence of Penetration. Pediatrics, 124, e403-e409. https://doi.org/10.1542/peds.2008-3053

Donaruma, M. (2019). Sexual Abuse. In J. S. Sanfilippo, E. Lara-Torre, \& V. Gomez-Lobo (Eds.), Sanfilippo's Textbook of Pediatric and Adolescent Gynecology (pp. 282-291). CRC Press. https://doi.org/10.1201/9781315147659-25

Felitti, V. J., Anda, R. F., Nordenberg, D. et al. (1998). Relationship of Childhood Abuse and Household Dysfunction to Many of the Leading Causes of Death in Adults. The Adverse Childhood Experiences (ACE) Study. American Journal of Preventive Medicine, 14, 245-258. https://doi.org/10.1016/S0749-3797(98)00017-8

Finkel, M. A. (2008). "I Can Tell You Because You're a Doctor”. Pediatrics, 122, 442. https://doi.org/10.1542/peds.2008-1416

Finkel, M. A., \& Alexander, R. A. (2011). Conducting the Medical History. Journal of Child Sexual Abuse, 20, 486-504. https://doi.org/10.1080/10538712.2011.607406

Finkelhor, D., Ji, K., Mikton, C., \& Dunne, M. (2013). Explaining Lower Rates of Sexual Abuse in China. Child Abuse \& Neglect, 37, 852-860.

https://doi.org/10.1016/j.chiabu.2013.07.006

Finkelhor, D., Turner, H. A., Shattuck, A., \& Hamby, S. L. (2015). Prevalence of Childhood Exposure to Violence, Crime, and Abuse: Results from the National Survey of Children's Exposure to Violence. JAMA Pediatrics, 169, 746-754.

https://doi.org/10.1001/jamapediatrics.2015.0676

Glaser, B., Strauss, A., \& Strutzel, E. (1968). The Discovery of Grounded Theory: Strategies for Qualitative Research. Nursing Research, 17, 364. https://doi.org/10.1097/00006199-196807000-00014

Greeley, C. S., Chuo, C. Y., Kwak, M. J. et al. (2016). Community Characteristics Associated With Seeking Medical Evaluation for Suspected Child Sexual Abuse in Greater Houston. The Journal of Primary Prevention, 37, 215-230. https://doi.org/10.1007/s10935-016-0416-9

Hassan, M., Gary, F. A., Hotz, R., Killion, C., \& Vicken, T. (2015). Young Victims Telling Their Stories of Sexual Abuse in the Emergency Department. Issues in Mental Health Nursing, 36, 944-952. https://doi.org/10.3109/01612840.2015.1063026

Heger, A., Ticson, L., Velasquez, O., \& Bernier, R. (2002). Children Referred for Possible Sexual Abuse: Medical Findings in 2384 Children. Child Abuse \& Neglect, 26, 645-659. https://doi.org/10.1016/S0145-2134(02)00339-3

Heyman, G. D., Ding, X. P., Fu, G., Xu, F., Compton, B. J., \& Lee, K. (2020). Young Children Selectively Hide the Truth About Sensitive Topics. Cognitive Science, 44, e12824. https://doi.org/10.1111/cogs.12824

Kellogg, N. D., Menard, S. W., \& Santos, A. (2004). Genital Anatomy in Pregnant Adolescents: "Normal” Does Not Mean "Nothing Happened". Pediatrics, 113, e67-e69. https://doi.org/10.1542/peds.113.1.e67

McElvaney, R., Greene, S., \& Hogan, D. (2014). To Tell or Not to Tell? Factors influencing Young People's Informal Disclosures of Child Sexual Abuse. Journal of Interpersonal Violence, 29, 928-947. https://doi.org/10.1177/0886260513506281 
Oates, R. K., Jones, D. P., Denson, D., Sirotnak, A., Gary, N., \& Krugman, R. D. (2000). Erroneous Concerns about Child Sexual Abuse. Child Abuse \& Neglect, 24, 149-157. https://doi.org/10.1016/S0145-2134(99)00108-8

Pereda, N., Guilera, G., Forns, M., \& Gómez-Benito, J. (2009). The Prevalence of Child Sexual Abuse in Community and Student Samples: A Meta-Analysis. Clinical Psychology Review, 29, 328-338. https://doi.org/10.1016/j.cpr.2009.02.007

Scott, H. K., \& Cogburn, M. (2020). Peer Play. StatPearls Publishing.

Seaver, M. R., Freund, K. M., Wright, L. M., Tjia, J., \& Frayne, S. M. (2008). Healthcare Preferences among Lesbians: A Focus Group Analysis. Journal of Women's Health, 17, 215-225. https://doi.org/10.1089/jwh.2007.0083

Shapiro, R. A., \& Makoroff, K. L. (2006). Sexually Transmitted Diseases in Sexually Abused Girls and Adolescents. Current Opinion in Obstetrics and Gynecology, 18, 492-497. https://doi.org/10.1097/01.gco.0000242950.09997.ca

Siegel, R. M., Schubert, C. J., Myers, P. A., \& Shapiro, R. A. (1995). The Prevalence of Sexually Transmitted Diseases in Children and Adolescents Evaluated for Sexual Abuse in Cincinnati: Rationale for Limited STD Testing in Prepubertal Girls. Pediatrics, 96, 1090-1094.

Sika-Bright, S., \& Nnorom, C. C. (2013). The Perception of Children on Child Sexual Abuse: The Case of Children in Some Selected Schools in the Cape Coast Metropolis, Ghana. Advances in Applied Sociology, 3, 246-252.

https://doi.org/10.4236/aasoci.2013.36033

Sjöberg, R. L., \& Lindblad, F. (2002). Limited Disclosure of Sexual Abuse in Children Whose Experiences Were Documented by Videotape. American Journal of Psychiatry, 159, 312-314.

Sorsoli, L. (2010). “I Remember”, “I Thought”, “I Know I Didn’t Say”: Silence and Memory in Trauma Narratives. Memory, 18, 129-141. https://doi.org/10.1080/09658210903168046

Stoltenborgh, M., van Ijzendoorn, M. H., Euser, E. M., \& Bakermans-Kranenburg, M. J. (2011). A Global Perspective on Child Sexual Abuse: Meta-Analysis of Prevalence around the World. Child Maltreatment, 16, 79-101. https://doi.org/10.1177/1077559511403920

Talwar, V., Lavoie, J., \& Crossman, A. M. (2019). Carving Pinocchio: Longitudinal Examination of Children's Lying for Different Goals. Journal of Experimental Child Psychology, 181, 34-55. https://doi.org/10.1016/j.jecp.2018.12.003 